\title{
FURTHER NOTE ON GASTROMEGALY FROM DUODENAL ILEUS
}

\author{
BY
}

REGINALD MILLER, M.D., F.R.C.P.,

Physician, St. Mary's and Paddington Green Children's Hospitals, London, and

\author{
H. COURTNEY GAGE, L.R.C.P., M.R.C.S., \\ Radiologist, St. Mary's Hospital, London.
}

Early in 1930 two cases were shown under the title of 'gastromegaly' by one of us (R.M.) before the Section for the Study of Diseases of Children of the Royal Society of Medicine ${ }^{1,2}$. In the same year we together recorded in this journal ${ }^{3}$ nine cases of the same type under the title of ' Gastromegaly and Chronic Duodenal Ileus in children.' The word ' gastromegaly' was used to connote an enlarged and hypertrophied stomach which is the most striking feature in these children, and in our paper we claimed that the abnormality of the stomach was secondary to some degree of obstruction in the latter part of the duodenum where this passes under the root of the mesentery and (usually) the superior mesenteric artery (chronic duodenal ileus or arterio-mesenteric compression). In the two years that have passed since our paper appeared, although we have had the pleasure of seeing three cases with medical colleagues and friends, so far as we know no instance of the condition has been exhibited or recorded. From this we infer that the evidence we brought forward of the presence of an obstructive factor in these cases, and more particularly of its site and nature, has failed to carry conviction to others. Nor does this surprise us: we recall that we had great difficulty in recognizing the obstructive element in our early cases, and that it was only by operation on two cases in our series that its position and nature were disclosed.

In the present paper we bring forward two new items of evidence in support of our view that arterio-mesenteric compression is the correct explanation of our cases of gastromegaly. First, we record the case of a baby who died on the ninth day of life with symptoms suggestive of duodenal atresia, and in whom post-mortem examination discovered a definite degree of obstruction of the duodenum as it passed under the root of the mesentery. Secondly, we produce skiagrams taken in the case of a girl aged eight years in which the symptoms, signs and reaction to treatment are the same as in our previously published cases. The skiagrams show the duodenum quite clearly and suggest the presence of obstruction in its third part.

Gastromegaly syndrome.-Before going further it will be well to give as briefly as possible the salient features of gastromegaly cases as described at length in our previous paper.

The most constant early symptom is that of refusal of food rather than vomiting, although in some instances vomiting occurred early enough to raise a suspicion of hypertrophic pyloric stenosis. In its early days the baby feeds extremely slowly, 
never welcomes its bottles and usually fails to finish them: only if food is pressed on it does vomiting occur. When it does, the vomiting is forcible in type. Bile may or may not be recognizable in the vomit: it is by no means constant. In the second year, as the child gets old enough to have solids added to its liquid food and to be pressed to take more than it wants, vomiting becomes more troublesome and tends later to occur in attacks accompanied by high fever, much prostration, and often diarrhœa with thick sodden mucus in the stools. The vomit is projected with force, and may show the presence of food taken many hours previously. In addition it contains a great excess of mucus, indicating the presence of gastritis. As a result of the anorexia and the vomiting attacks the child gains weight with extreme slowness, and its physical development is of the frailest though actual stunting in height is not a prominent feature. In between the vomiting attacks the child's appetite remains deplorably bad, its breath foul and its tongue coated. Persistent hiccup may be a conspicuous sympton.

In the minority of cases vomiting is even less conspicuous, and the attacks of fever are associated chiefly with diarrhœa in which the motions contain thick sodden mucus, evidently from the stomach rather than the intestine.

On examination the abdomen is rather protuberant, but it is noticeable that it is chiefly prominent in its upper part. The outline of the enlarged stomach is often to be seen, and on palpation the wall of the stomach gives the sensation of being thickened. After a meal or after inflation of the stomach by a draught of soda-water peristaltic waves may be seen passing from left to right in the region of the stomach. Neither fullness nor peristalsis of the duodenum can be observed, at all events in the absence of vomiting. In addition to these signs splashing in the stomach can be elicited at almost any hour of the day.

X-ray examination shows enlargement of the stomach, the body of the organ often protruding beyond and so obscuring the pyloric end and duodenal cap. In addition hyperperistalsis is well marked, and the emptying time of the stomach much prolonged.

Under treatment by means of a dry diet and an alkaline antiseptic mixture considerable improvement occurs. Vomiting attacks become less frequent or disappear, the tongue cleans, the appetite improves and the hiccups cease to be peculiarly troublesome. The older children do better under treatment than the younger ones since there is probably some tendency for spontaneous improvement to occur at or after the age of six or seven years of age. If treatment is started for the first time at about this age, the improvement obtained may be dramatic (see Case 2 below), since it coincides with the time of a slow spontaneous tendency towards improvement.

Present cases.- The details of the two cases on which we wish to base certain arguments are now given.

Case 1. Barbara S., aged 5 days, was admitted on November 21st, 1931, to Paddington Green Children's Hospital under the care of one of us (R.M.), having been referred by Dr. T. P. Lewis of Braintree, Essex, as a possible case of duodenal atresia.

The child was born at full-term and though small was apparently healthy. From the first she had vomited 'everything,' breast and cow's milk. On two occasions the vomitus had contained black or brownish-black material, the nature of which was unexplained. The vomiting continuing the baby was referred to hospital.

On admission the baby was small and rather dehydrated. On being fed it squirmed about as if in discomfort until relieved by vomiting. Apparently the bulk of the food taken was expelled. The vomit showed no bile or other abnormal colouration. Much mucus was present in it. Irregular gastric peristalsis was observed but it was rather obscured by the perpetual wriggling of the child. A small hard lump was felt far down in the right loin. This was not mistaken for a hypertrophied pylorus, but its nature was not understood. It was probably the tip of one of the lowest ribs left uncovered by the absence of the right kidney as was discovered at autopsy. The motions were dark (meconium). 
Vomiting continued. Most feeds were ejected soon after ingestion, though occasionally one would be retained until the next feed. In an effort to see how the stomach emptied an opaque meal was given. This (Fig. 1 and 2) showed that very little food passed into the intestine, though two days later traces of barium were recognized in the stool.

On November 23rd the child was going downhill and in the hope that the obstruction might be due to some condition such as a band that could be dealt with easily, laparotomy was performed. The stomach was found to be large, the pylorus

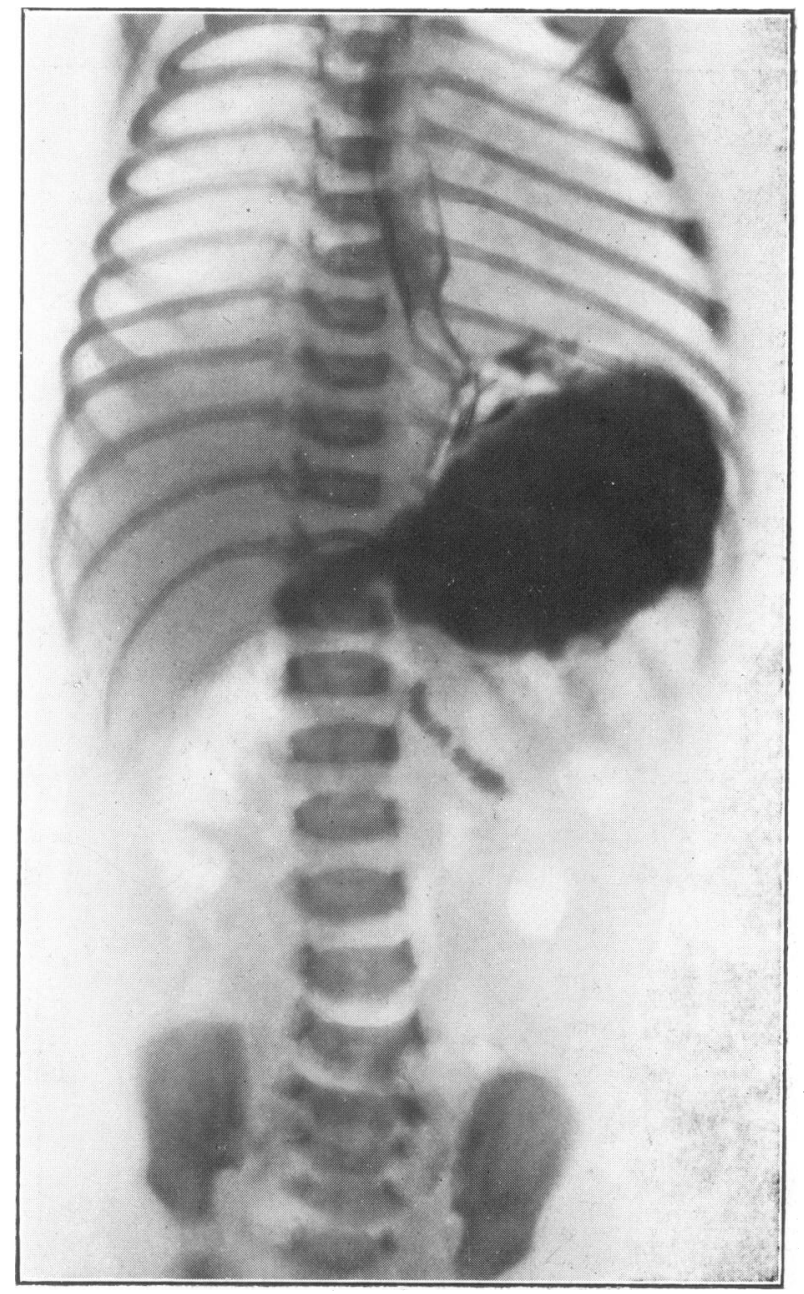

Fig. 1.-Case 1, opaque meal at 15 minutes; prone.

normal, the duodenum large and the jejunum definitely small; but in the few moments available to the surgeon he could not localize the cause of obstruction. The child died next day in hyperpyrexia, aged 8 days.

Radiographic examination (November 21st, 1931). By means of a stomach tube $1 \frac{1}{2} \mathrm{oz}$. of a fluid suspension of barium sulphate were introduced into the stomach. On screening vigorous gastric peristaltic waves were seen.

The first film (Fig. 1) was taken at 15 minutes in the prone position. It shows a flocculent shadow of the barium, due to admixture in the stomach with the contents present before the barium meal was given. The outline of the shadow is 
irregular and does not indicate in silhouette the true contour of the stomach, but only a puddle resting on the anterior gastric wall. It does not reach the fundus, neither does it fill the pyloric antrum as this part passes to the right and backwards towards the duodenal cap. This indicates that the stomach is larger than the patch of barium at first sight suggests. The vigorous peristalsis has already ceased, although only a few minims of the meal have been passed on into the small intestine, to be seen in the commencement of the jejunum as a quite narrow streak. No part of the duodenum is seen at this examination, but it is of interest to note that the streak in the jejunum is at most not more than half the width of the short part of the duodenum seen in Fig. 2.

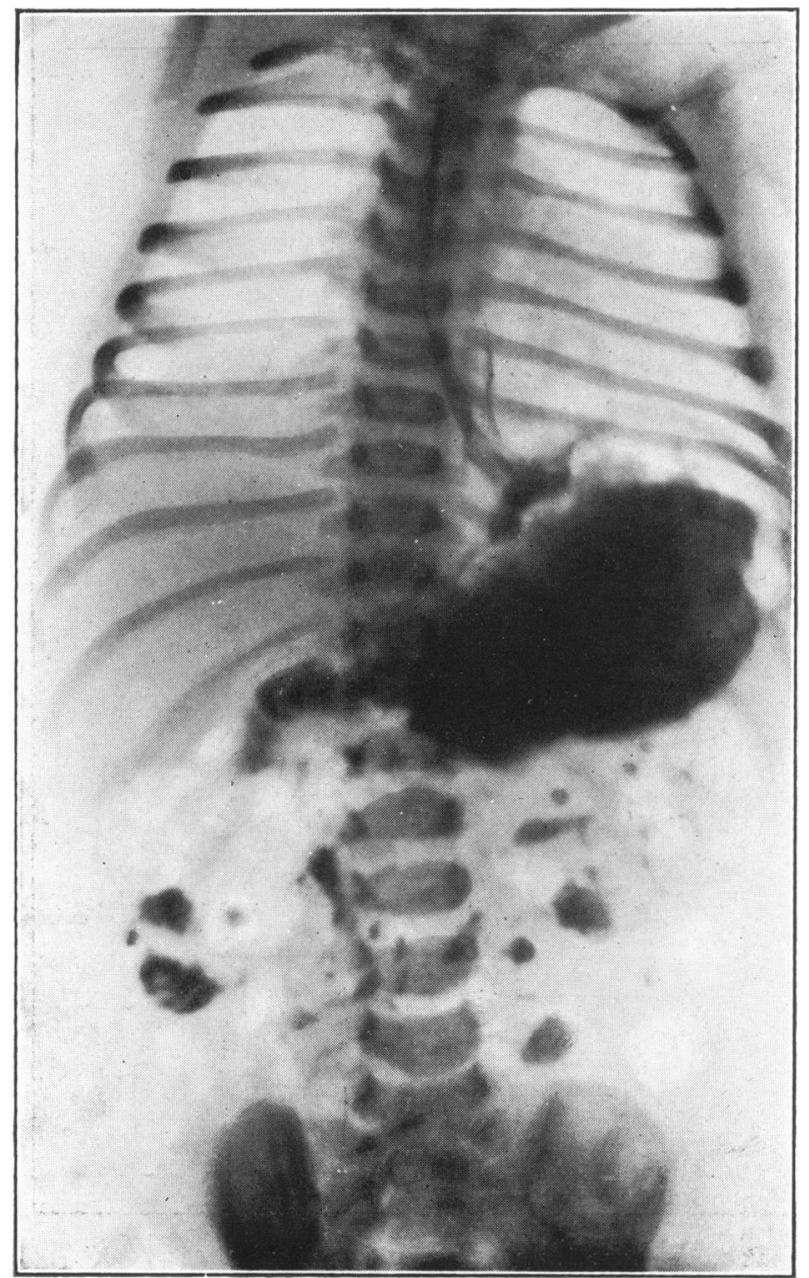

Fig. 2.-Case 1, opaque meal at 35 minutes; prone.

The second film (Fig. 2) was taken at 35 minutes. The general appearance of the stomach remains unchanged and only a few more minims of the meal have passed on, to be seen as flecks distributed throughout the small intestine. This film, however, shows the duodenal cap and a small quantity of the meal in the second or descending part of the duodenum.

No examination was made to determine the exact emptying time of the stomach, the presence of gastric delay being already established. Normally the stomach commences to empty even before ingestion is complete. 
Autopsy. The body of a very small emaciated baby showing an abdominal wound. On opening the abdomen the stomach was seen to be moderately enlarged and the duodenum, also enlarged, was in proportion to the size of the stomach. Hypertrophy of the gastric wall could not be recognized with any assurance. The jejunum was definitely smaller than the duodenum, between one-half and two-thirds of the width of the duodenum, and the change in the size of the intestine came abruptly at the level of the crossing of the gut by the mesenteric root and the superior mesenteric artery. The right kidney was completely absent: the left enlarged.

Except for the compression exercised on the duodenum the disposition of the root of the mesentery and its vessels appeared normal.

The points in the case related above to which we call special attention are these. In the first place the anatomical picture found post mortem was exactly the same as that found in our two previous cases at operation (Cases 1 and 2 in our former paper). Although clearly the degree of obstruction by arterio-mesenteric compression was more severe than in our previous cases, yet by. no means could the present case be classed amongst the examples of congenital megaduodenum in which the duodenum may attain the size of a 'second stomach.' Herein lies a matter of practical importance for in the cases of our group there seems no possibility of performing a duodeno-jejunostomy as may be done to relieve a condition of megaduodenum. Secondly, the radiographic examination, although admittedly undertaken in circumstances of difficulty, proved the presence of obstruction to the evacuation of the stomach but gave no certain evidence as to the site or nature of the obstruction. In this it was exactly in line with the results of our previous cases, though in this fatal case the character of the obstruction was unmistakable post mortem.

Case 2. Betty B., aged 8 years: referred by Dr. W. Horsfall Chesters, of Bromley, Kent, for vomiting attacks accompanied by high fever. First seen July 23rd, 1931.

Child was born at full-term, weighing $7 \frac{1}{2} \mathrm{lb}$. From the first there was great difficulty in getting her to take her bottles. She had to have much smaller feeds than an ordinary child as she refused to take more. If pressed she would be sick, the vomit being projected and always containing mucus and sometimes bile. Her gain in weight was very slow, seldom more than $2 \mathrm{oz}$. a week. At 11 months she refused bottles altogether and they had to be given up. At a year she was very small but plump. She was not regarded as an ill child during her first year: her frailty and peculiar feeding were attributed to the comparatively elderly age of the parents who had been married for seven years before pregnancy occurred.

During the second year great difficulty was experienced in introducing solid food into the diet. Vomiting still occurred if food was pressed. The meals were extremely small ('an eggcupful'), and an hour and a half would be taken to eat a small slice of bread and butter.

In her third year she had whooping-cough very severely and after that the vomiting became worse. Since then she has had bouts of vomiting every 4 to 6 weeks, coming on without warning. The first thing noticed wrong is usually fever, the temperature running up to considerable height, often $105^{\circ}$. Very quickly the vomiting will start and will last perhaps 48 hours, the vomit being full of mucus and often containing bile. The temperature will not regain normal for 4 or 5 days. With the vomiting there is nearly always diarrhoa: the stools contain much thick sodden mucus, 'like skins.' The motions are sometimes putty coloured.

Apart from these attacks the tongue is perpetually coated and the breath foul. Hiccups are frequent. The bowels are very regular: no aperient is ever needed. 
Seen in July, 1931, she complained of the same symptoms as above. She was a good height for her age, but very thin and rather underwieght. Her complexion was good. Her tongue was coated. The abdomen was blown out in its upper part, where the outline of a large stomach could be seen. Splashing was easily elicited. Gastric peristalsis was observed.

Radiographic Examination. A 10-ounce barium meal was given of Allenbury food, milk and chocolate.

The tone of the stomach is exceptionally good, and hyperperistalsis is present throughout the whole of the examination. In spite of this there is an appreciable residue in the stomach at 4 hours and a trace at 8 hours. There is a definite tendency for the pyloric portion to pass well over to the right, but owing to the strong contraction of the pyloric antrum the duodenal cap is not obscured as so frequently happened in the previous series of cases. The duodenal cap is normal, and a normal pyloric canal is to be seen in the first exposure of the serial film, and also on the film taken at 2 hours.

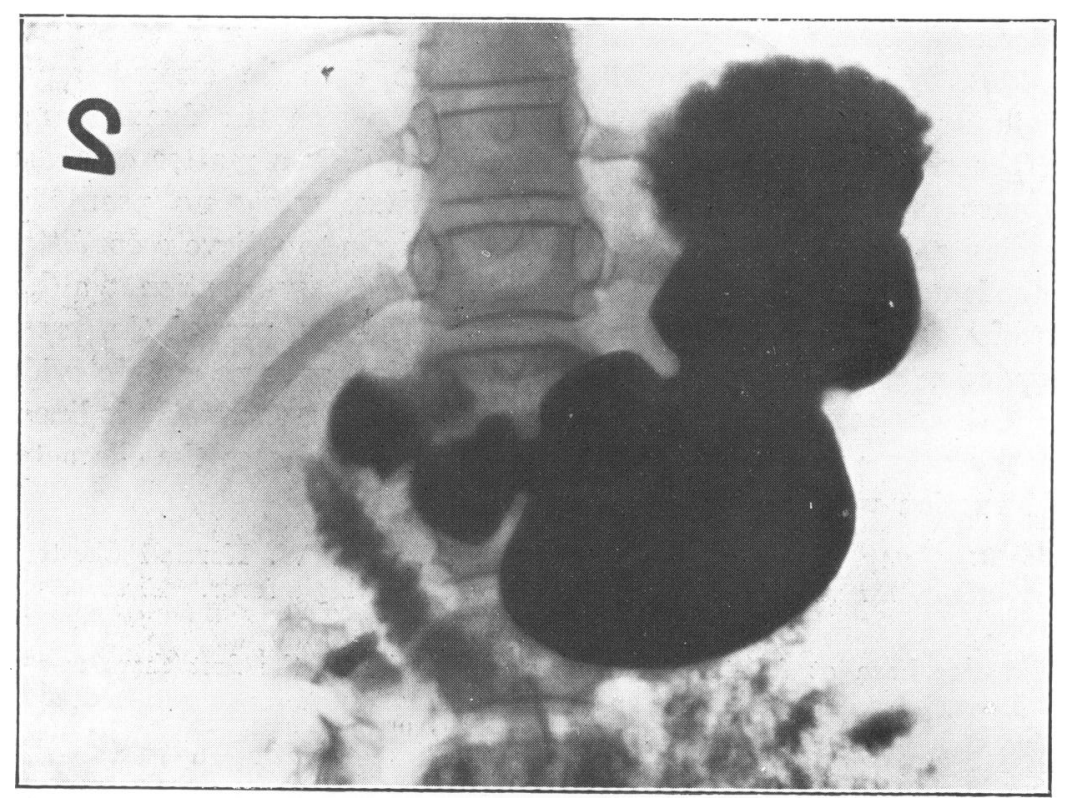

Fig. 3.-Case 2, opaque meal at 2 hours; prone. (See Fig. 5.)

The film at 2 hours (Fig. 3) also shows barium in the descending and commencement of the transverse part of the duodenum, terminating just before the mid-line is reached, and it is interesting to note that it gets wider as this part is reached. There is a definite suggestion of ' cogwheel' formation, but it is certainly not so squarecut as it is seen to be in adults with duodenal stasis.

Barium is also to be seen in this segment in the 4 hour film (Fig. 4), but unfortunately its termination is obscured by the barium in the transverse colon at the right border of the vertebrae. It certainly does not appear at the left border, and it probably terminates in the mid-line as in the 2-hour film.

There is no ileal stasis, and the passage of the meal through the colon presents no unusual features.

Treatment. The girl was treated on the lines described in our previous papers by means of a dry diet, fluids 3 hours or more after meals, and an alkaline antiseptic mixture after food.

Course. Seen again in February, 1932, a great improvement was reported. She had gone seven months without being sick, but had then awakened one morning 
and vomited bile and mucus, and had passed putty coloured motions. She had gained several pounds in weight. The hiccups and splashing were less, according to the mother. Splashing could, however, easily be elicited. The distension of the stomach appeared less, and the tongue cleaner. The mother stated that if the medicine were left off for three or four days the tongue coated over and the breath became foul. There was still no real appetite: the meals were taken in normal time, but only about a quarter of the normal amount of food was consumed.

In this case we lay stress on the fact that radiographic evidence suggesting obstruction in the latter part of the duodenum was obtained in a typical example of gastromegaly with characteristic symptoms dating from birth in the usual way.

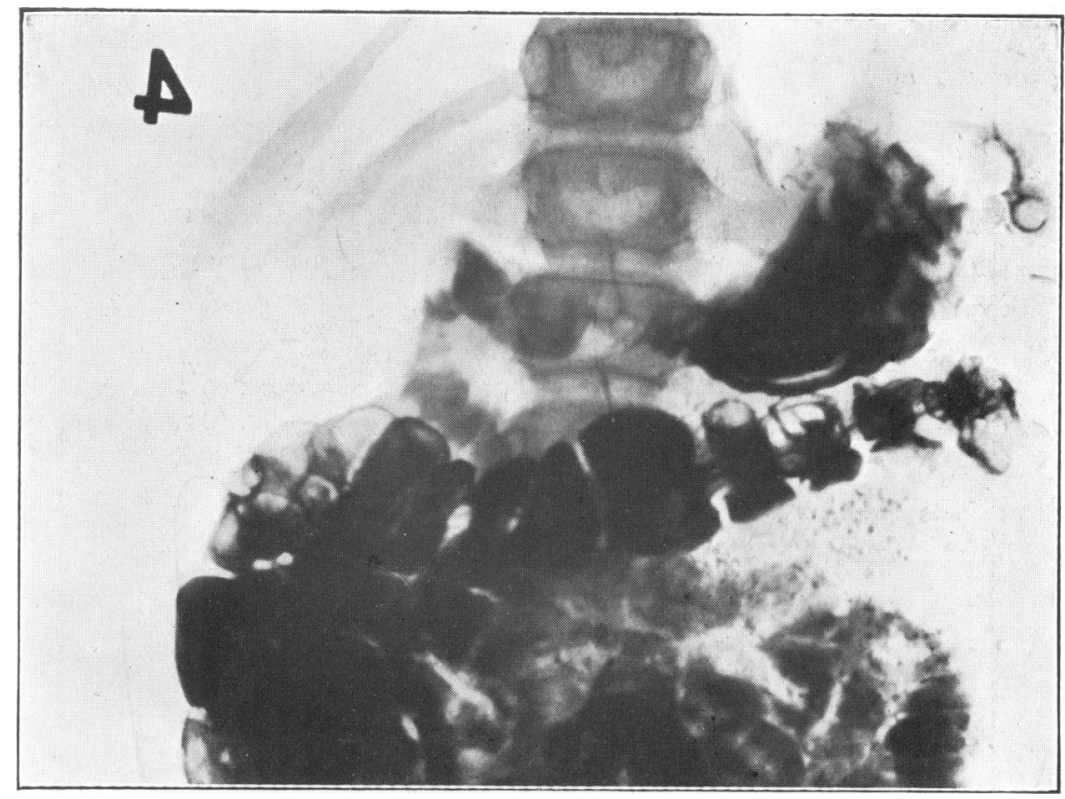

FIg. 4.-Case 2, opaque meal at 4 hours; prone. (See Fig. 5.)

Discussion.

We now proceed to discuss seriatim the points of difficulty in connection with these cases which we have termed 'gastromegaly' and explain as secondary to some degree of obstruction to the duodenum from arteriomesenteric compression (chronic duodenal ileus).

1. The presence of organic obstruction.-We take first the essential point that there is in our cases some degree of organic obstruction high in the alimentary tract, and that we are not dealing with examples merely of such conditions as pylorospasm, chronic gastritis or atonic dyspepsia. To us the evidence on this point seems quite satisfactory and to be recognized with no great difficulty in practice once its possibility is in mind.

Clinically the stomach may be seen to be enlarged, often causing prominence of the upper part of the abdomen. Hypertrophy of the wall of the stomach is not only suggested by the feel of the organ through the abdominal wall, but is definitely proved by the presence of visible gastric 
peristalsis which may be observed after a meal or a drink of soda-water. The large size of the vomits and their projectile character also suggest an enlarged and hypertrophied stomach, such as can only be conceived as secondary to some form of obstruction to its evacuation. Confirmatory evidence of such

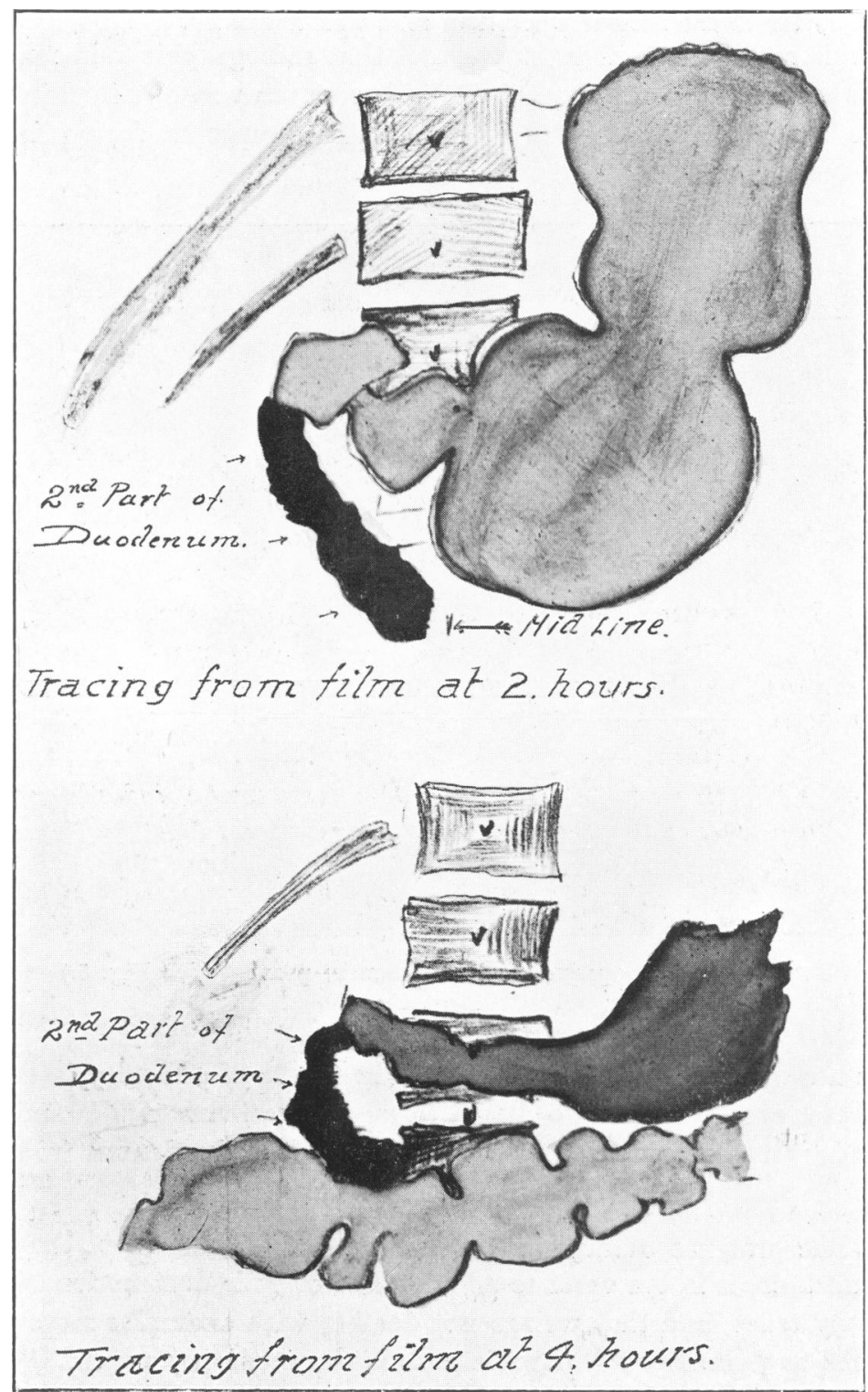

Fig. 5.-Marked tracings of films shown in Figures 3 and 4.

obstruction is found in the fact that, in spite of over-active gastric peristalsis, there is considerable gastric stasis. Clinical proof of this is the presence in the vomit of food taken many hours previously. The perpetual splashing noises which can be heard on shaking the abdomen at almost any time 
confirm this. Lastly, the presence of chronic gastritis in a baby or young child does strongly suggest the presence of some high obstruction (cf. the gastritis of hypertrophic pyloric stenosis).

Radiographic evidence of organic obstruction is equally clear. The stomach is abnormally large, often so greatly enlarged is it that the body of the organ covers and obscures the pylorus and duodenal cap. Hyperperistalsis is seen, but in spite of this the emptying time of the stomach is unduly long. In some instances only half the meal may have passed on in $3 \frac{1}{2}$ hours. With improvement under treatment the stomach, although still enlarged, becomes smaller and more normal in shape, and the hyperperistalsis may succeed in bringing the emptying time within the normal limit.

Finally, organic obstruction was found in both the cases of our series submitted to operation (Cases 1 and 2 of our previous paper), and in our. single fatal case (see Case 1 above).

We conclude, therefore, that in our cases of gastromegaly the presence of some organic obstructive factor is clearly proved, laying particular emphasis on the association of persistent hyperperistalsis with well marked stasis in the enlarged stomachs of these children.

2. The duodenal site of the obstruction.-'To prove the presence of obstruction in these cases is far easier than to determine its exact situation, and we must now discuss the evidence for and against our contention that it is in the latter part of the duodenum.

Evidence for DUOdenal site.-The following arguments may be put forward in favour of this view.

(a) On clinical and radiological grounds we can be sure that the obstruction is in these cases high in the digestive tract, and there is seldom any real difficulty in excluding the stomach itself as the seat of the obstruction by means of the X-ray examination. This is certainly true once experience has been gained of this type of case, and taken by itself it is an important step towards incriminating the duodenum.

(b) Interference with the flow of bile is to be noted in many instances. This does not always take the form of the vomiting of bile, as will be discussed later, but may show itself by gross, though transient, interference with the absorption of fat in the intestine. This is sufficient in degree to make it a wise rule to feed these children with a diet containing a low, rather than a high, proportion of fat.

(c) In our previous paper we stated that the attack of vomiting showed ' nothing sufficiently peculiar to distinguish them as of duodenal origin.' We should now be inclined to modify this statement, and to say that the rapid onset of very high fever, especially if accompanied by the vomiting of bile or the passage of putty-coloured stools, is rather suggestive of the severe toxicosis of duodenal stasis, 
(d) Duodenal obstruction was found in the two operation cases previously reported, and in the fatal case recorded here. We also think that the radiographic evidence in Case 2 above is quite satisfactory as proving the duodenal situation of the obstruction. Except that in the fatal case the condition was much more severe than in the others, we are not able to distinguish any difference between these four ' proved' cases and the rest of our series.

Arguments against duodenal site.-We come now to consider the arguments that can be advanced against the duodenal situation of the obstruction in these cases.

(a) Undoubtedly the chief difficulty in accepting our interpretation of these cases lies in the fact that the opaque meal cannot be relied on to demonstrate the presence of duodenal obstruction. It is certainly true that in nearly all cases, at all events in the absence of vomiting at the time of the examination, the duodenum is not seen. In about twenty cases the only instance in which the duodenal obstruction has shown is that of Case 2 reproduced here.

The question at issue is, therefore, whether these usually negative results preclude the diagnosis of duodenal obstruction. In our view they do not, for several reasons.

In the first place the radiographic results were as negative in our ' proved' cases as in those unverified by operation or post-mortem examination. Even in our fatal case (Case 1 above), although the obstruction was much more severe than in any of the others, the $\mathrm{X}$-ray examination gave no clear indication of the duodenal obstruction which was so unmistakable post mortem. Secondly, except in the fatal case, we have had no opportunity of examining by radiograms any case during an actual bout of vomiting. Perhaps in such a phase good fortune would lead to a clear picture of duodenal obstruction. Thirdly, our present Case 2, showing a successful radiogram, is exactly in line with the unsuccessful cases as far as clinical history and physical signs are concerned. Lastly, if we grant for the moment that the obstruction is due to duodenal ileus, it is well known that in adult examples of this condition there is considerable difficulty in making a satisfactory diagnosis by means of $\mathbf{X}$-ray examination. A recent paper by R. P. Rowlands ${ }^{4}$ has emphasized this once more. The reason for this difficulty will be shown later in discussing the congenital and accessory factors producing the obstruction.

Although, therefore, in our earlier cases we felt considerable hesitation in accepting as true that duodenal obstruction of this type could pass unrecognized in skiagrams, we are now sure that this may be so. In this connection it is to be realized that the enlargement of the duodenum is comparatively slight: in none of our series of cases was there a real megaduodenum.

(b) Another difficulty lies in the fact that the vomiting of bile is by no. means necessarily a conspicuous symptom. In the very severe cases of other 
authors, associated with megaduodenum, the vomiting of bile has been often a very obvious and suggestive feature, but in our own group, where the obstruction is of much less degree, this is not the case. Even in the fatal instance recorded here, no bile was recognized in the vomits from the fifth to the ninth day when death occurred. There was a history of dark vomits soon after birth. It was suspected that these contained altered blood, but it may have been bile or meconium-stained fluid. In Case 2 above, bile was sometimes vomited apart from food, but in the majority of our cases biliousness of the vomit has not struck the parents as peculiar. Frank ${ }^{5}$ has noticed the same thing in cases of duodenal obstruction and suggests that the colour of the bile is lost by dilution.

Whatever the explanation may be we do not regard this difficulty as disproving the presence of duodenal obstruction. In the first place there has been no difference in this point between the cases proved by operation or post-mortem examination and the others; and secondly, there is evidence, as we have already pointed out, that the flow of bile may be interfered with in the fairly common occurrence of pale and fatty stools.

3. Nature of the duodenal obstruction.--If duodenal obstruction be accepted as the explanation of our cases, there is no great difficulty in accepting arterio-mesenteric compression as the cause of the obstruction. In very severe cases giving rise to urgent symptoms in the earliest days of life, as in Case 1 above, it must be, as far as we can see, impossible to exclude duodenal stenosis, obstruction by band or gross malformation of the mesentery; but in the less severe types, with their history of congenital anorexia, vomiting attacks, chronic gastritis and very slow development, it is not easy to think of any condition so likely to be present as that of chronic duodenal ileus such as we found in our ' proved' cases. As things go the syndrome we have sketched out is a tolerably constant one, sufficiently so to convince us that the same lesion is responsible for all the cases.

Arterio-mesenteric compression has been described as a cause of megaduodenum in a fair number of instances (see Table 1 in our previous paper $)^{*}$, so that there is nothing unexpected in its causing an obstruction of a milder degree.

There is one other point which to our minds is in favour of chronic duodenal ileus as the cause of the gastromegaly syndrome which we will now discuss.

4. Congenital and accessory factors.-In the production of obstruction by duodenal ileus there are two possible sets of factors. First, there is the strictly congenital factor, the malformation by which the space for the passage of the duodenum is narrowed by the arterio-mesenteric compression. Secondly, there is the accessory factor whereby the space is still further reduced by a drag on the mesentery from a distended stomach or colon.

* An interesting example of megaduodenum of this type which survived until the age of six years and was then successfully dealt with by duodeno-jejunostomy has been recently published by $\mathrm{U}$. Camera ${ }^{6}$. 
In our cases it seems that the influence of both these factors can be recognized. In our best marked examples there is no doubt some degree of obstruction present from birth. Its severity varies in the different cases but it remains in evidence for many years until, probably by the natural growth of the parts, it ceases to give rise to obstructive symptoms. But it also seems that the accessory factor of mesenteric drag comes into play. The influence of a distended stomach in our cases is quite clear: to press food on the child is to produce vomiting or initiate one of its ' attacks.' The influence of a distended colon is much more difficult to trace, but it is noticeable that in several of our cases the colon has been particularly voluminous and in one instance (Case 9 of our previous paper) was enormous. It is probable that the dual character of the obstruction in these cases accounts for the uncertain radiographic results and the inconstancy of bilious vomiting in them.

From these considerations we submit that the explanation that we have advanced for our cases of gastromegaly, namely, the presence of chronic congenital duodenal ileus, does fit in with the observed facts particularly well. And in this connection we recall that D. P. D. Wilkie ${ }^{7}$ found that in many of his adult cases of chronic duodenal ileus there was a history of symptoms during childhood, followed by a period of freedom lasting for many years.

\section{Summary.}

Two fresh pieces of evidence are brought forward to support the view published in this journal two years ago, that chronic (congenital) duodenal ileus or arterio-mesenteric compression is the cause of a syndrome in children in which enlargement and hypertrophy of the stomach (gastromegaly) is the most prominent physical sign.

These consist of (1) post-mortem evidence in a baby dying on the ninth day of life; and (2) radiographic evidence in a child of eight years old.

We discuss the arguments against our hypothesis which are based on the practical difficulty of demonstrating duodenal ileus by radiology and other means; and we dismiss them on the grounds that the same difficulties are encountered even in the examples which are verified as correct by operation or post-mortem examination.

We are indebted to Dr. Tierrens, radiologist, and Miss Frost, radiographer, to the Paddington Green Children's Hospital, for the films of the first case recorded here.

\section{REFERENGES.}

1. Miller, R., Proc. R. Soc. Med., Lond., 1929-30, XXIII, (Sect. Study of Dis. Child.), 33.

2. Miller, R., Loc. cit., 66.

3. Miller, R., \& Gage, H. C., Arch. Dis. Childh., Lond., 1930, V, 83.

4. Rowlands, R. P., Guy's Hosp. Gaz., Lond., 1930, XLIV, 93.

5. Frank, E. S., Ztschr. f. Kinderh., Berlin, 1913, IX, 99.

6. Camera, U., Arch. d. méd. des enf., Paris, 1930, XXXIII, 583.

7. Wilkie, D. P. D., Brit. J. Surg., Bristol, 1921, IX, 204; Brit. Med. J., Lond., 1922, ii, 1219; Amer. J. Med. Sci., Philad., 1927, CLXXIII, 643, 